\title{
Broad phenotypic impact of the effects of transgenerational heat stress in dairy cattle: a study of four consecutive generations
}

\author{
Joel Ira Weller ${ }^{1,2}$, Ephraim Ezra ${ }^{1}$ and Moran Gershoni ${ }^{2^{*}}$ (D)
}

\begin{abstract}
Background: Global warming has increased the frequency of heat stress in livestock. Although heat stress directly leads to negative effects on production and reproduction traits in dairy cattle, the transgenerational transition of these changes is poorly understood. We hypothesized that heat stress in pregnant cows might induce epigenetic modifications in the developing embryo germ cells, which, in turn, might lead to phenotypic effects in the offspring. Here, we examined whether transgenerational effects of heat stress contribute to the phenotypic expression of economic traits in Israel dairy cattle. Since heat stress in Israel occurs specifically between June and October, first we examined the association of the month of birth of $F_{1}$ cows (pregnancy of the $F_{0}$ dam) with the performance of the $\mathrm{F}_{2}$ and $\mathrm{F}_{3}$ female offspring. Then, we calculated an annual heat stress index and examined the association of the heat stress index during the pregnancy of the $F_{0}$ dam with the performance of her $F_{2}$ and $F_{3}$ offspring. Finally, we examined intergenerational interactions of heat stress by comparing the performance of $\mathrm{F}_{3}$ cows according to the pregnancy seasons of the $F_{0}$ and $F_{1}$ animals.

Results: We found a significant association of the month of birth, season of pregnancy, and heat stress index of $\mathrm{F}_{0}$ females, with the performance of their $F_{2}$ and $F_{3}$ progenies, which suggests a true transgenerational effect. The most significant transgenerational effects were on fat yield and concentration, dystocia, still-birth, and maturation.

Conclusions: These findings suggest that heat stress during pregnancy affects the performance of offspring, regardless of life circumstances in at least the last three generations. Therefore, heat stress can reduce selection efficiency in breeding programs and may have economic significance in livestock.
\end{abstract}

\section{Background}

There is growing evidence for climate change and global warming in recent decades, which include increased temperatures and a higher incidence of heat waves [1]. Environmental factors such as temperature changes can directly affect the health and productivity of dairy cows, and chronic heat stress accounts for up to $25 \%$ loss in

\footnotetext{
${ }^{*}$ Correspondence: gmoran@volcani.agri.gov.il

${ }^{2}$ The Volcani Center, Department of Ruminant Science, Institute

of Animal Sciences, Agricultural Research Organization, 7505101 Rishon LeZion, Israel

Full list of author information is available at the end of the article
}

milk production [2]. In addition, data from the Israeli herd book demonstrates a clear seasonal effect on conception rate $(\mathrm{CR})$ over the two last decades, with an almost twice-higher $\mathrm{CR}$ during the winter compared to the summer. An average elevation of $1.5{ }^{\circ} \mathrm{C}$ during the summers of 2010, 2012, and 2015 caused an additional decrease of 5\% in CR [3]. Measurements of the temperature humidity index (THI) are used to assess the risk of heat stress in livestock. There are different formulas to calculate THI, and the most common one uses the combination of temperature and relative humidity $(\mathrm{RH})$ as follows: original author(s) and the source, provide a link to the Creative Commons licence, and indicate if changes were made. The images or other third party material in this article are included in the article's Creative Commons licence, unless indicated otherwise in a credit line to the material. If material is not included in the article's Creative Commons licence and your intended use is not permitted by statutory regulation or exceeds the permitted use, you will need to obtain permission directly from the copyright holder. To view a copy of this licence, visit http://creativecommons.org/licenses/by/4.0/. The Creative Commons Public Domain Dedication waiver (http://creativeco mmons.org/publicdomain/zero/1.0/) applies to the data made available in this article, unless otherwise stated in a credit line to the data. 


$$
(1.8 \times \mathrm{T}+32)-(0.55-0.0055 \times \mathrm{RH}) \times(1.8 \times \mathrm{T}-26)
$$

where $\mathrm{T}$ is the ambient temperature. Several studies have shown that an increase in THI modifies metabolic heat production in cattle differently depending on the cow productivity. Furthermore, breakpoints of maximal and minimal THI of 79.6 and 70.3, respectively, were shown to cause a significant acceleration in the overall death rate [4]. In addition to the direct effects of heat stress and other environmental factors on the animal, recent evidence suggests that maternal circumstances during pregnancy contribute to the phenotype of the offspring at adulthood, and may be transmitted to the next generations. For instance, a reduction in body size and in milk production during first lactation was observed for $\mathrm{F}_{1}$ heifers born to heat-stressed dams during late gestation, as compared to heifers born to cows of similar age and weight from calvings that were cooled during pregnancy $[5,6]$. This evidence suggests that the exposure of $\mathrm{F}_{1}$ fetuses to heat stress during the pregnancy of their $\mathrm{F}_{0}$ dams can affect their phenotype in adulthood. Therefore, it is plausible that heat stress during gestation affects the epigenetics programming of the gametes in the developing fetus, and can contribute to the variation in phenotypic expression of $\mathrm{F}_{2}$ and $\mathrm{F}_{3}$ progeny.

"Transgenerational effects" are defined as observed effects on the organism that cannot be attributed to genetics or environmental effects on the individual. For example, an environmental stress can directly affect the embryo in utero and, in the female embryos, their developing oocytes. Therefore, in the case of female transmission, only altered phenotypes that occur in the third generation after exposure to environmental stress could be attributed to transgenerational inheritance. Thus if an $F_{0}$ gestating female is exposed to environmental stress, the $\mathrm{F}_{3}$ generation is the first generation not directly exposed to this factor $[7,8]$. Shorter timescale effects can be described as intergenerational, although they sometimes share mechanisms with transgenerational effects [9]. Evidence for intergenerational effects in cattle has recently been demonstrated in a small cohort of $\mathrm{F}_{2}$ granddaughters whose grandmothers were not cooled during late gestation. This study revealed a reduction in milk production and in number of days in the herd for granddaughters of not-cooled $\mathrm{F}_{0}$ cows, which may have caused a significant economic loss [10]. While limited in commercial populations of livestock, evidence for intergenerational effects comes mostly from studies in human and animal models. For example, Torrens et al. [11] showed that during the pregnancy of female Wistar rats, protein restriction caused elevated blood pressure and endothelial dysfunction in the $\mathrm{F}_{2}$ offspring throughout the maternal line. In mice, Jimenez-Chillaron et al. [12] found that maternal undernutrition during pregnancy of the $\mathrm{F}_{0}$ female leads to reduced birth weight, reduced glucose tolerance, and obesity in $F_{1}$ and $F_{2}$ offspring and that the transmission of these intergenerational effects was sexspecific and likely mediated by epigenetic modification.

Intergenerational effects in "natural populations" were demonstrated mainly in humans. Offspring of women that were pregnant during the "Dutch famine" were found to have coronary heart diseases more frequently, raised lipids, altered clotting and obesity, obstructive airways disease, microalbuminuria and decreased glucose tolerance, in a gestation-trimester dependent manner [13]. Some of these effects also affect the $F_{2}$ offspring [14, 15]. Intergenerational effects of smoking and food supply were shown to affect $F_{2}$ offspring in a sex-specific manner in a comparative study that was conducted within the frame of the Överkalix cohorts in northern Sweden [16].

Evidence of transgenerational effects and their impact on individual health and performance in commercial livestock populations, their effects on selection, the species evolution, and the breeding programs are sparse. In the current study, we tested the hypothesis that effects of heat stress can be trans-generationally transmitted and affect the performance for production and reproduction traits in the offspring. To this end, we analyzed hundreds of thousands of records from the Israeli herd-book over four consecutive generations, which allowed us to examine the potential transmitting ability (PTA $=1 / 2$ of the estimated breeding value) of $\mathrm{F}_{3}$ cows depending on the exposure to heat stress of their $\mathrm{F}_{0}$ ancestors during their pregnancy.

\section{Methods}

\section{Traits analyzed}

We analyzed the genetic evaluation of the nine traits that are included in the Israeli breeding index, PD16, the PD16 index itself, fat and protein concentrations, and female sexual maturity. The composition of PD16 is summarized in Table 1. Fat and protein concentrations in milk, somatic cell score (SCS), female fertility and milk production persistency were evaluated as described previously $[17,18]$. All the traits included in PD16, except herd-life, were analyzed by a multi-trait animal model, with each parity considered as a separate trait. In addition to the additive genetic effects, the models included the effects of herd-year-season and parity. Then, the single parity evaluations were combined into a multi-parity index as described previously [17]. Herd-life was computed as the number of days from first calving to culling, and analyzed by a single-trait animal model. For cows that were not yet culled, expected herd-life was computed as described previously [19]. First and second parity calving ease 
Table 1 Composition of PD16, the Israeli breeding index

\begin{tabular}{llll}
\hline Trait & Index coefficient & Genetic SD & $\begin{array}{l}\text { Fraction of } \\
\text { the index }\end{array}$ \\
\hline Milk (kg) & 0 & 910 & 0.000 \\
Fat (kg) & 8.48 & 32.1 & 0.212 \\
Protein (kg) & 21.2 & 22.6 & 0.373 \\
Somatic cell score & -300 & 0.47 & 0.110 \\
Fertility (\%) & 26 & 7.15 & 0.145 \\
Persistency (\%) & 10 & 5.44 & 0.042 \\
Herd-life (days) & 0.6 & 205 & 0.096 \\
Maternal calving dif- & -3 & 5.46 & 0.013 \\
ficulty (\%) & & & \\
Maternal stillbirth (\%) & -6 & 2.21 & 0.010 \\
\hline
\end{tabular}

$S D$ standard deviation

${ }^{a}$ Computed as the product of the absolute value of index coefficient and the genetic SD for each trait, divided the sum of the index contributions for all traits

and rate of stillbirth were analyzed jointly by a multitrait animal model including the effects of the cow calving and of the sire of calf as described by Weller and Ezra [20]. Reliabilities of all the traits analyzed by the animal model were derived as described previously [17-20]. Fat and protein concentrations were derived from the evaluations of the production traits. Female maturing rate was estimated as the number of days from birth to first insemination. Genetic evaluations were not computed for this trait, and the phenotype was analyzed.

\section{Datasets analyzed}

In order to perform the desired statistical analyses, it was necessary to generate four datasets. The numbers of records in each dataset are in Table 2. Dataset 1 (GD month) included 175,171 Israeli Holstein cows with first parity freshening dates from January 1, 2009, through December 31, 2018. Only the cows that were daughters of Israeli Holstein bulls with valid first parity records for production traits and genetic evaluations were included. In the analyses of the effects of the birth month of the maternal grand-dam (MGD) for each trait, we included only the cows for which genetic evaluations of the granddam were available. Similarly, in the analyses of the effects of the maternal birth month, we included only the cows for which genetic evaluations of the dam were available.

Dataset 2 (Min-Max) included records on 75,477 cows for which the relevant ancestor, dam or grand-dam, was born from August through November. These months were selected, because preliminary results indicated that the main negative epigenetic effect was due to heat stress

Table 2 Number of cows with records, dams and maternal grand-dams (MGD) included in each analysis

\begin{tabular}{|c|c|c|c|c|c|c|}
\hline \multicolumn{2}{|l|}{ Data set } & \multirow[t]{2}{*}{ Trait } & \multicolumn{2}{|l|}{ Dam birth month } & \multicolumn{2}{|l|}{ MGD birth month } \\
\hline Number & Name & & Number of records & Number of dams & Number of records & Number of MGD \\
\hline \multirow[t]{6}{*}{1} & GD month & PD16 & 152,306 & 120,175 & 149,017 & 99,023 \\
\hline & & Milk production traits ${ }^{\mathrm{a}}$ & 175,171 & 134,722 & 171,404 & 109,462 \\
\hline & & Female fertility & 160,787 & 125,894 & 157,285 & 103,262 \\
\hline & & Persistency & 165,810 & 128,627 & 162,231 & 105,014 \\
\hline & & Herd-life & 174,262 & 134,179 & 170,535 & 109,074 \\
\hline & & Calving traits & 171,036 & 132,205 & 167,414 & 107,725 \\
\hline \multirow[t]{6}{*}{2} & Min-Max & PD16 & 65,261 & 50,943 & 60,161 & 40,045 \\
\hline & & Milk production traits & 75,477 & 57,330 & 68,173 & 43,801 \\
\hline & & Female fertility & 68,996 & 53,400 & 63,176 & 41,572 \\
\hline & & Persistency & 71,378 & 54,732 & 65,003 & 42,258 \\
\hline & & Herd-life & 75,077 & 57,086 & 67,815 & 43,622 \\
\hline & & Calving traits & 73,662 & 56,255 & 66,730 & 43,182 \\
\hline 3 & Maturing & Female maturing rate & 348,417 & 229,588 & 343,298 & 173,307 \\
\hline \multirow[t]{6}{*}{4} & GD season & PD16 & 133,472 & 120,175 & 133,472 & 99,023 \\
\hline & & Milk production traits & 150,796 & 122,668 & 150,796 & 101,595 \\
\hline & & Female fertility & 139,698 & 122,668 & 139,698 & 101,595 \\
\hline & & Persistency & 144,216 & 122,668 & 144,216 & 101,595 \\
\hline & & Herd-life & 150,034 & 122,668 & 150,034 & 101,595 \\
\hline & & Calving traits & 147,644 & 122,668 & 147,644 & 101,595 \\
\hline
\end{tabular}

${ }^{\mathrm{a}}$ Milk, fat, and protein production; fat and protein concentration; and somatic cell score 
during the second half of the pregnancy of the relevant ancestor.

Dataset 3 (Maturing) included 348,417 virgin heifers with first inseminations between January 1, 2008 and December 31, 2017, and age at first insemination between 275 and 729 days. As in dataset 1, only the heifers that were daughters of Israeli Holstein bulls and cows were included. In the analysis of the effect of the birth month of the dams, only the heifers with valid production records for their dams were included. As in the analysis of the effect of the birth month of the MGD, only the heifers with valid production records for their granddams were included.

Dataset 4 (GD season) included 150,796 cows with first parity freshening dates between January 1, 2008 and December 31, 2017, with genetic evaluations for the production traits, and genetic evaluations of their dams, sires and MGD. Three birth seasons, denoted 1, 2, and 3, were defined for the dams and MGD, i.e. December through March, April through July, and August through November, respectively.

\section{Seasonal heat stress score}

Thermal humidity index (THI) values were computed based on the ambient temperatures $(\mathrm{T})$ and the relative humidity $(\mathrm{RH})$ values recorded between 1995 and 2020 by the Israel Meteorological Service on five meteorological stations representing different climate zones in Israel: coastline and lowlands-Bet Dagan $(8 \mathrm{~km}$ south of Tel Aviv), the inland valleys-Neve Ya'ar, the Jordan River valley-Sodom, the Arava Desert-Hazeva and the mountains-Tzuba. THI was calculated for each set of records as previously described [21]:

$$
\begin{aligned}
\mathrm{THI}= & (1.8 \times \mathrm{T}+32)-(0.55-0.0055 \times \mathrm{RH}) \\
& \times(1.8 \times \mathrm{T}-26) .
\end{aligned}
$$

To test whether one representative station could be used as an indicator of THI across Israel for the summer period, we computed Pearson's correlations between equivalent THI measurements from the five stations. Correlations between the Bet Dagan station and the four other stations were all higher than 0.92. Based on these results, the Bet Dagan THI score was used as the representative $\mathrm{THI}$ for the entire country.

The seasonal heat stress score was calculated over a summer period from June 1 to September 30. Cows were assumed to be heat-stressed if the THI was higher than $72[22]$.

\section{Statistical analyses}

The datasets were analyzed by the general linear model procedure of the SAS software [23]. Each trait was analyzed separately. Because individual records are affected by many environmental factors, cows had different numbers of records, and because the repeat records on a cow were correlated, the dependent variable was the cow's PTA for all traits with genetic evaluations. The model used for genetic evaluation of all the traits included the effects of herd-year-season, merit of mates and parity, except herd-life for which only a single record is generated per cow. The analysis model used for dataset 1 (GD month) to estimate the effect of the birth month of the dam was as follows:

$$
\mathrm{PTA}_{\mathrm{ijk}}=\mathrm{M}_{\mathrm{i}}+\mathrm{D}_{\mathrm{j}}+\mathrm{DB}+\mathrm{DP}+\mathrm{e}_{\mathrm{ijk}},
$$

where PTA $\mathrm{Aijk}_{\mathrm{ij}}$ is the PTA of cow $\mathrm{k}$ for each of the traits analyzed, $M_{i}$ is the effect of birth month $i$ of the cow, $D_{j}$ is the effect of birth month $j$ of the cow's dam, DB is the linear effect of the dam's birth date, DP is the linear effect of the dam's PTA, and $\mathrm{e}_{\mathrm{ijk}}$ is the random residual. Records are corrected for calving month prior to genetic evaluation, but are not corrected for birth month [17-20]. Therefore, a class effect for the cow's birth month was included in Eq. (2). The linear effect of the dam's birth date was included to account for genetic trend, and the effect of the dam's PTA was included to account for possible confounding between the dam's genetic value and her birth month. For the analysis of the MGD's birth month, the models included the MGD's birth month, instead of the dam's birth month, as a class effect, and the linear effects of the MGD's birth date and PTA. The significance of all the effects in all the models analyzed were determined by the F-test of the "Type-III" sum of squares, which is the significance of each effect relative to the residual variance after correction for all the other effects included in the model.

Four analyses were computed for dataset 2 (Min-Max) for each trait including the effect of the number of days within the birth year of the dam or grand-dam during which heat stress was recorded at the Bet Dagan weather station during the coolest time of day (MIN): THI $>72$ at $\sim$ 5:00 am and during severe heat stress (MAX): THI $>79$ at any time of the day. Since these effects are only relevant for cows that are pregnant during the summer, only the records with grand-dams born in August through November were included. The numbers of days for each criterion from 1995 to 2015 are in Table 3. The analysis model for the effects of MIN and MAX on the birth year of the dam was:

$$
\mathrm{PTA}_{\mathrm{ijk}}=\mathrm{M}_{\mathrm{i}}+\mathrm{D}_{\mathrm{j}}+\mathrm{H}+\mathrm{B}+\mathrm{A}+\mathrm{e}_{\mathrm{ijk}},
$$

where $\mathrm{H}$ is the linear effect of the heat stress parameter, i.e. MAX or MIN, recorded during the birth year of the grand-dam, B is the linear effect of the cow's birth date, $\mathrm{A}$ is the linear effect of the dam's age in days at 
Table 3 Number of days in the summer season in which severe heat stress (THI > 79) was measured during any time of the day (MAX), or heat stress ( $\mathrm{THI}>72$ ) during the coolest time of day $(\mathrm{MIN}, \sim 5: 00)$ at the Bet Dagan weather station

\begin{tabular}{lll}
\hline Year & MAX & MIN \\
\hline 1995 & 40 & 22 \\
1996 & 46 & 28 \\
1997 & 16 & 13 \\
1998 & 51 & 34 \\
1999 & 32 & 32 \\
2000 & 41 & 31 \\
2001 & 47 & 30 \\
2002 & 56 & 42 \\
2003 & 45 & 31 \\
2004 & 42 & 26 \\
2005 & 47 & 33 \\
2006 & 53 & 28 \\
2007 & 58 & 40 \\
2008 & 55 & 57 \\
2009 & 54 & 47 \\
2010 & 76 & 74 \\
2011 & 68 & 49 \\
2012 & 87 & 77 \\
2013 & 48 & 57 \\
2014 & 55 & 52 \\
2015 & 67 & 54 \\
\hline
\end{tabular}

the birth of her daughter, and the other terms are as defined for Eq. (2). The terms B and A were included to account for the fact that both MAX and MIN increased over the time period analyzed. The model for the effects of MIN and MAX on the birth year of the MGD was the same, except that the effect of the dam's birth month was replaced by the effect of the MGD's birth month, and the dam's age at the birth of her daughter was replaced by the grand-dam's age at the birth of her granddaughter.

In the analyses of dataset 3 (Maturing), the dependent variable was the number of days from birth to first insemination. The analysis model used for estimating the effect of the dam's birth month was:

$$
\mathrm{DF}_{\mathrm{ijk}}=\mathrm{M}_{\mathrm{i}}+\mathrm{D}_{\mathrm{j}}+\mathrm{B}+\mathrm{e}_{\mathrm{ijk}} \text {, }
$$

where $\mathrm{DF}_{\mathrm{ijk}}$ is the number of days from birth to first insemination for cow $\mathrm{k}$, and all other terms are as defined previously. To estimate the effect of the MGD's birth month, the effect of the dam's birth month was replaced by the effect of the MGD's birth month. Both models included the linear effect of the heifer's birth date to account for possible genetic trend over time.
Table 4 Frequencies of birth season of cows per birth season of their dam and maternal grand-dam (MGD)

\begin{tabular}{|c|c|c|c|c|}
\hline & \multicolumn{3}{|c|}{ Cow's birth season } & \multirow[t]{2}{*}{ Total } \\
\hline & 1 & 2 & 3 & \\
\hline \multicolumn{5}{|c|}{ Dam's birth season } \\
\hline 1 & 25,249 & 11,104 & 10,810 & 47,163 \\
\hline 2 & 6583 & 18,378 & 14,082 & 39,043 \\
\hline 3 & 17,858 & 9072 & 38,045 & 64,975 \\
\hline \multicolumn{5}{|c|}{ MGD's birth season } \\
\hline 1 & 18,633 & 12,952 & 15,781 & 47,366 \\
\hline 2 & 9420 & 12,513 & 15,584 & 37,517 \\
\hline 3 & 21,637 & 13,089 & 31,572 & 66,298 \\
\hline Total & 49,690 & 38,554 & 62,937 & 151,181 \\
\hline
\end{tabular}

Dataset 4 (GD season) was analyzed by two models. The first model was:

$$
\mathrm{PTA}_{\mathrm{ijkl}}=\mathrm{M}_{\mathrm{i}}+\mathrm{SD}_{\mathrm{j}}+\mathrm{SM}_{\mathrm{k}}+\mathrm{B}+\mathrm{GD}+\mathrm{GS}+\mathrm{e}_{\mathrm{ijkl}},
$$

where $S D_{j}$ and $S M_{k}$ are the class effects of the birth season of dam $j$ and MGD k, GD and GS are the PTA's of dam $j$ and sire $k$ as covariates, and the other terms are as defined previously. The effects B, GD and GS were included to account for genetic trend and possible confounding between season of birth and the genetic evaluation of the ancestors. In the second model, this dataset was analyzed including the interaction between the dam's and MGD's season of birth. The number of cows included in each analysis varied slightly depending on whether valid records were available for each trait for all the effects included in the analysis. The numbers of records, dams and grand-dams included in each model are in Table 2.

Frequencies of birth season of cows per birth season of their dam and grand-dam are in Table 4. The mean calving interval in Israel ranges from 410 to 430 days. For both frequencies, season 3 had the largest and season 2 the smallest number of births. This is apparently due to the significant reduction in conception rate in August and September [24], which should result in fewer births in the early summer. In both cases, the distribution of birth seasons between ancestors and progeny was not random according to the Chi-squared test $(\mathrm{P}<0.0001)$, and the frequencies of ancestors and progeny being born in the same season were higher than expected by random distribution.

Figure 1 shows the mean PTA of the cows' parents for PD16 and the number of cows in dataset 4 that are born each month per cows' birth month. The frequencies of births per month are in Fig. 1 with fewer births in the early 


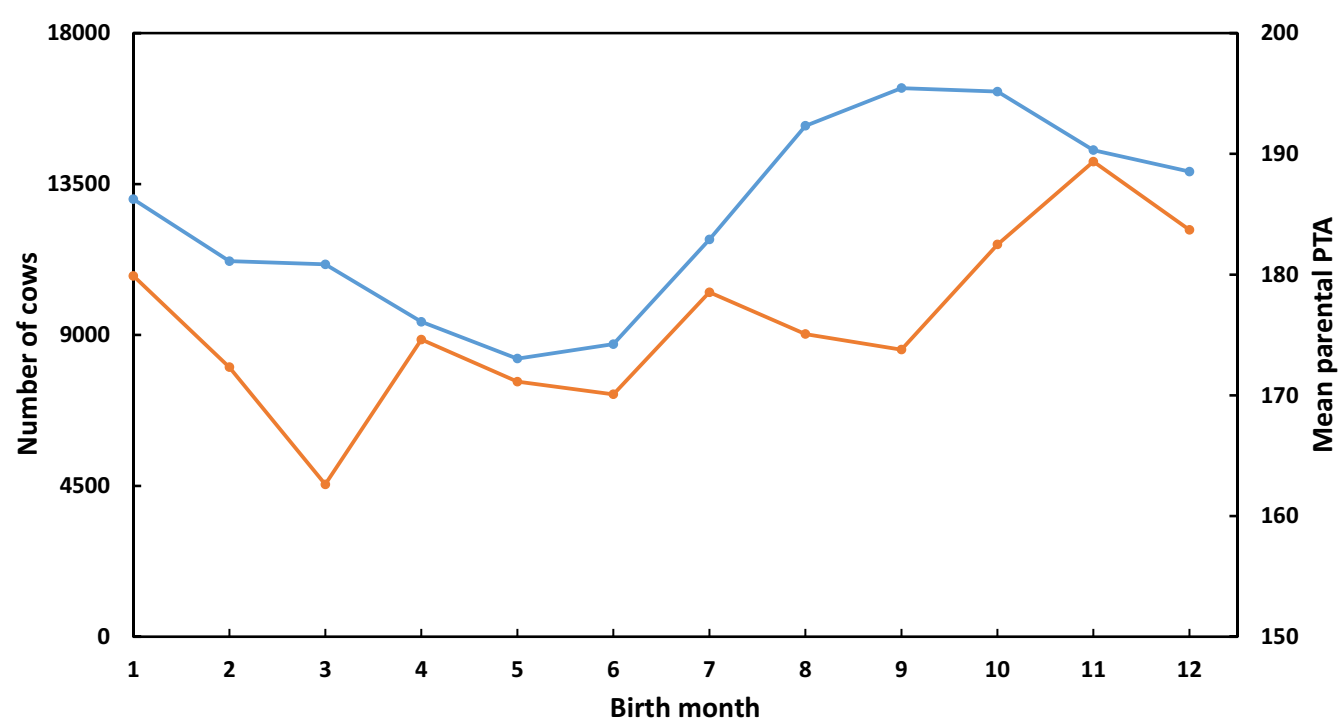

Fig. 1 Mean potential transmitting ability (PTA) of the cows' parents for the Israeli breeding index (PD16) and number of cows in dataset 4 per cows' birth month. Blue line: number of cows per birth month; brown line: mean parental PTA for PD16 per birth month

summer, which as mentioned above, is due to a major reduction in conception rate in the late summer [24]. The significant differences in mean parental PTA between birth month $(\mathrm{P}<0.0001)$ are somewhat surprising, and were not previously noted. It is not clear why the mean parental PTA should be highest for cows born in November and lowest for those born in March, i.e. for parents mated in February and June, respectively. Considering that 10 complete calendar years were analyzed, the general positive trend may be partly due to the mean increase of 60 PTA units in PD16 per year, which represents five units per month.

\section{Results}

In Israeli dairy cattle, heat stress during the day occurs mainly from June through October, as outlined in [25]. Thus, the cow's birth month can be used as an indicator of when exposure to heat stress occurred during her dam's pregnancy. Thus, we computed the effects of the birth month of the $F_{1}$ and $F_{2}$ cows (i.e. the effects of the pregnancy of the $\mathrm{F}_{0}$ and $\mathrm{F}_{1}$ cows) on the performance of $\mathrm{F}_{3}$ progeny (Fig. 2) after correction for confounding environment and genetic effects. Twelve production and reproduction traits and the PD16 index, were analyzed. Cow reliabilities for milk production traits ranged from

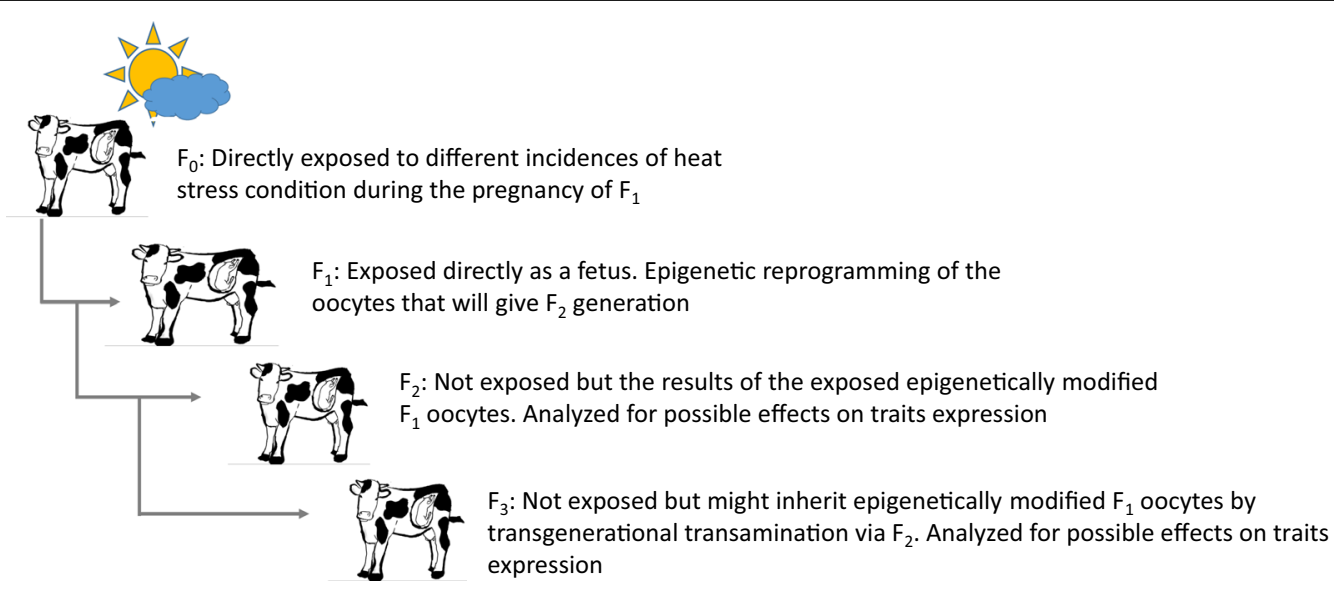

Fig. 2 Schematic representation of the experimental model 
Table 5 Root mean square error values and probability to reject the null hypothesis for significance of the dam and maternal grand-dam (MGD) birth month effects in each analysis of data sets 1 and 3

\begin{tabular}{llll}
\hline Trait & $\begin{array}{l}\text { Root mean square } \\
\text { error }^{\mathbf{a}}\end{array}$ & Probability & \\
\cline { 3 - 4 } & & Dam & MGD \\
\hline PD16 & 163 & $10^{-4 *}$ & $10^{-4 *}$ \\
Milk & 165 & $10^{-4 *}$ & 0.0248 \\
Fat & 8.57 & $10^{-4 *}$ & $10^{-4 *}$ \\
Protein & 4.58 & $10^{-4 *}$ & $10^{-4 *}$ \\
Fat \% & 0.072 & $10^{-4 *}$ & $0.0033^{*}$ \\
Protein \% & 0.029 & $0.0017^{*}$ & $\mathrm{NS}^{\mathrm{b}}$ \\
SCS & 0.126 & $10^{-4 *}$ & $0.0017^{*}$ \\
Female fertility & 1.58 & $\mathrm{NS}$ & $\mathrm{NS}$ \\
Persistency & 1.27 & 0.0341 & $\mathrm{NS}$ \\
Herd-life & 37.5 & 0.0262 & $\mathrm{NS}$ \\
Dystocia & 0.972 & $10^{-4 *}$ & $10^{-4 *}$ \\
Stillbirth & 0.645 & $10^{-4 *}$ & $10^{-4 *}$ \\
Maturing rate & 0.0715 & $10^{-4 *}$ & $10^{-4 *}$ \\
\hline
\end{tabular}

" Significant after Bonferroni's adjustment $(P<0.005)$; the Bonferroni correction was computed based on the 13 traits analyzed

${ }^{a}$ Derived from the dam analyses

${ }^{\mathrm{b}}$ Not significant

0.35 to 0.73 with a mean of 0.55 , but $90 \%$ of the reliabilities were between 0.48 and 0.61 . Root mean square error values and the probabilities of rejecting the null hypothesis for significance of the effects of the dams' and maternal grand-dams' (MGD) birth months in each analysis of datasets 1 and 3 are in Table 5 . Effects of the pregnancy period of both the $F_{0}$ and $F_{1}$ maternal ancestors on the performance of $\mathrm{F}_{3}$ cows were significant for fat and protein yield, \%fat, SCS, calving traits, maturing rate and the cow's PD16 score, but not for female fertility, milk production persistency and herd-life. The effect of the birth month of the dams on milk production was significant, but not that of the MGD.

The trends of the $\mathrm{F}_{3}$ cows' PTA for fat and protein yield as functions of the $F_{1}$ and $F_{2}$ cows' birth month are shown in Fig. 3. The PTA for fat and protein yield were higher for the F3 cows whose $F_{1}$ and $F_{2}$ cows were born between March to June. Thus, the corresponding pregnancy periods of the $F_{0}$ and $F_{1}$ cows were mainly during fall and winter, with no or little exposure to heat stress. The $F_{1}$ and $F_{2}$ cows that were born between August and December are the progeny of the $F_{0}$ and $F_{1}$ cows that had a late pregnancy during the summer and early fall, and were thus likely to have been exposed to a high incidence of heat stress conditions during the second pregnancy semester. Figure 3 shows a corresponding reduction in fat and protein yield of the $\mathrm{F}_{3}$ progeny of these cows. These trends are not similar to the parent average PTA for the PD16 plotted in Fig. 1.

Results for dystocia and still-birth are given in Fig. 4. Cows whose $F_{1}$ and $F_{2}$ ancestors were born between June and September displayed the most economically negative effect (positive values). This observation suggests a negative effect on calving traits for cows whose $F_{0}$ and $\mathrm{F}_{1}$ ancestors have their last trimester pregnancy during the summer, compared to cows whose $\mathrm{F}_{0}$ and $\mathrm{F}_{1}$ ancestors have not been exposed to heat stress or have been exposed to heat stress early in gestation.

To directly assess the impact of heat load during the pregnancy of the $F_{0}$ and $F_{1}$ cows on their progenies, we devised an annual summer heat stress score, i.e. the incidence of days with heat stress conditions per summer. Trends in annual heat stress score are plotted in Fig. 5. Analysis of the annual trends in MIN and MAX heat stress scores per year revealed a significant elevation in heat stress scores throughout the last two decades. MIN showed a greater rate of increase than MAX, with an average addition of 2 days with heat stress condition per year $\left(\mathrm{r}^{2}=0.63 ; \mathrm{P}=0.0002\right)$.

The type III sum of squares $F$ probabilities for the effect of MIN and MAX in the birth year of the dams or MGD are in Table 6. The dams' age was significant $(\mathrm{P}<0.05)$ for all traits, except for SCS. The dams' birth month was significant $(\mathrm{P}<0.05)$ for $\mathrm{PD} 16$, fat and protein yield, \%fat, SCS and calving traits. The heat stress score of the dams' birth year was significant for all traits, except for PD16 and herd-life, in at least one of the two analyses. The MGDs' birth month was significant only for SCS, which is not surprising, since only the months August through November were included. The effects of the MGDs' birth date and age were significant for all traits $(\mathrm{P}<0.05)$. There was a significant association of the summer MIN scores during the $\mathrm{F}_{0}$ cows' pregnancy with the performance of their $F_{3}$ progeny for PD16, milk and fat yield, fat and protein concentration, persistency, herd-life and dystocia, but not for the other traits analyzed, including protein yield, which is the main trait under selection. Thus, annual differences in heat stress incidence during the summer experienced by the $F_{0}$ and $F_{1}$ cows had a general impact on performance of their progenies.

The models considered so far included only the main effects of the birth month of the ancestors and their exposure to heat stress conditions. However, different combinations of the pregnancy periods of the $\mathrm{F}_{0}$ and $F_{1}$ cows might affect the performance of the $F_{3}$ progenies differently, i.e., significant interactions may occur between the effects of the dam and grand-dam season of pregnancy. To answer this question, we divided the year into three birth seasons. Season 1 denoting birth during winter, with dam second-semester pregnancy during 


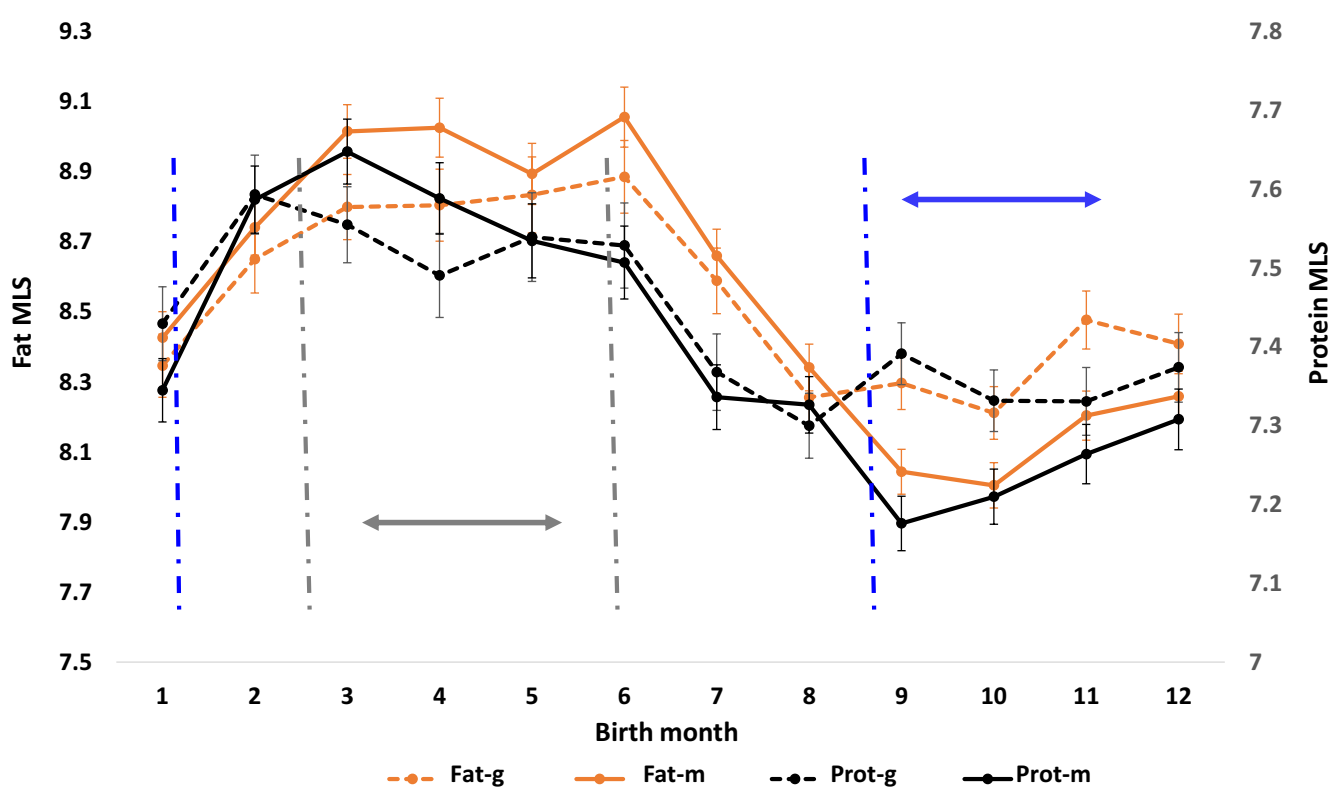

Fig. 3 Trends in milk composition traits of the $F_{3}$ cows per pregnancy month of their $F_{0}$ and $F_{1}$ ancestors. Left and right $y$-axes represent the mean least squares (MLS) of the potential transmitting abilities (PTA) for fat and protein yields, respectively, as functions of the birth month of the cows' dams and maternal grand-dams. "fat-g" and "prot-g" are MLS of the cows' fat and protein yields, respectively, as functions of the maternal grand-dams' birth month; and "fat-m" and "prot-m" are MLS of the cows' fat and protein yields, respectively, as functions of dams' birth month. The error bars are the MLS standard errors. Gray and blue vertical dashed lines denote the positive (March to June) and negative (September to January) trend thresholds, respectively. Gray and blue double-headed arrows denote the boundaries of the threshold intervals

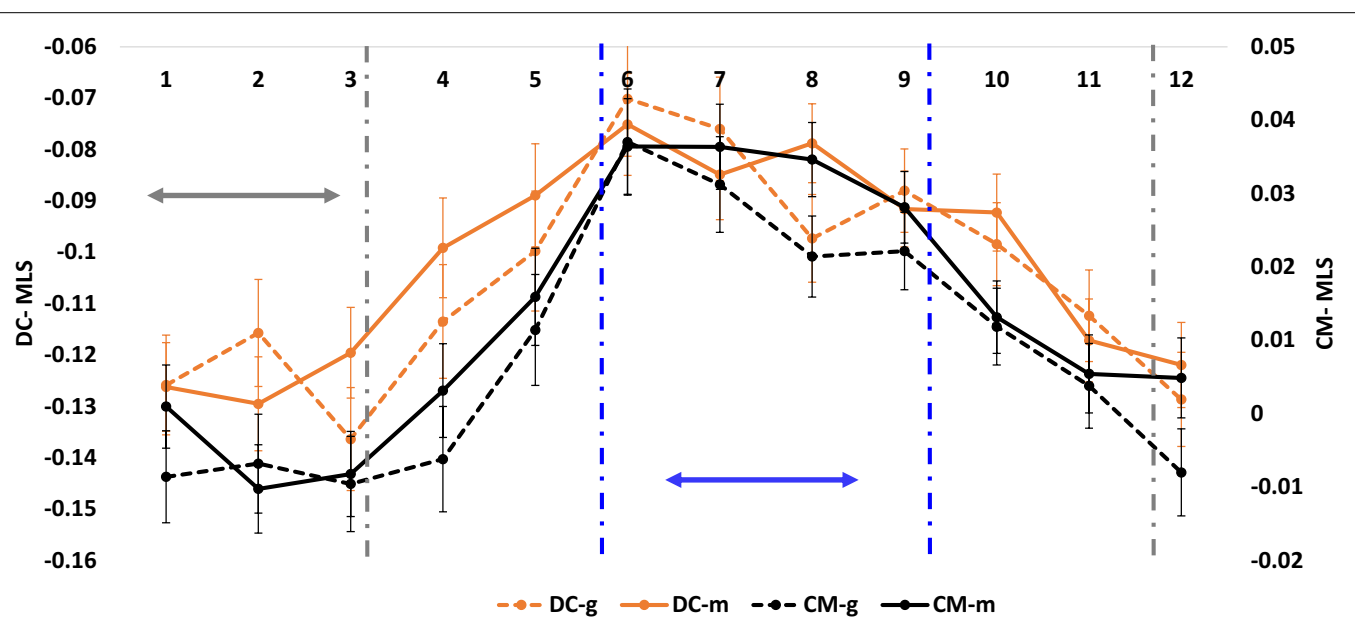

Fig. 4 Trends in calving associated-traits of the $F_{3}$ cows per pregnancy month of their $F_{0}$ and $F_{1}$ ancestors. Left and right $y$-axes represent the mean least squares (MLS) of potential transmitting abilities (PTA) for dystocia and stillbirth, respectively, as a function of the birth month of the cows' dams and maternal grand-dams. "DC-g" and "CM-g" are the MLS of the cows' dystocia and calf mortality, respectively, as functions of the maternal grand-dams' birth month; and "DC-m" and "MC-m" are MLS of the cows' dystocia and calf mortality, respectively, as functions of dams' birth month. The error bars are the MLS standard errors. Gray and blue dashed lines denote positive (December to March) and negative (June to September) trend thresholds, respectively. Gray and blue arrows denote the boundaries of the threshold interval

fall-winter; season 2 denoting birth season during spring with dam pregnancy mostly during fall-spring, and no overlap with summer; and season 3 denoting birth during the fall, with dam second pregnancy semester during the summer. Figure 6 shows the trends of the performance of the $\mathrm{F}_{3}$ cows for PD16; milk, fat and protein yield and $\%$ fat; with different combinations of pregnancy seasons of the $F_{0}$ and $F_{1}$ cows. The performances of the $F_{3}$ cows 


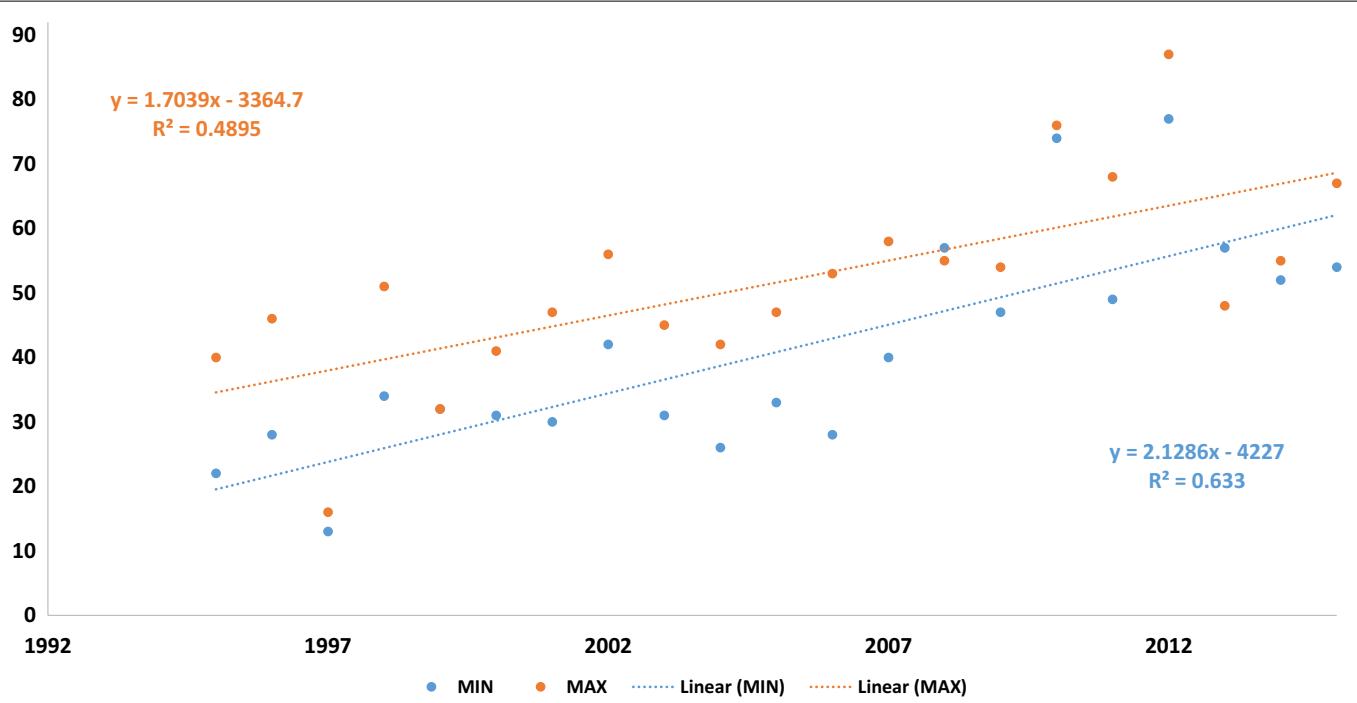

Fig. 5 Trends in annual heat stress score per year. Dotted lines represent the maximal heat stress score (severe heat stress condition at the daily maximal temperature, orange) and the minimal heat stress score (heat stress condition at the daily minimal temperature, blue). The $x$-axis represents year and $y$-axis the computed heat stress score

Table 6 Type III sum of squares F probabilities for the effect of number of days in the dam's or maternal grand-dam's (MGD) birth year for which heat stress $(\mathrm{THI}>72)$ was recorded during the coolest time of day ( $\mathrm{MIN}, \sim 5: 00)$ or severe heat stress $(\mathrm{THI}>79)$ was recorded during any time of the day (MAX) at the Bet Dagan weather station

\begin{tabular}{|c|c|c|c|c|}
\hline \multirow[t]{2}{*}{ Trait } & \multicolumn{2}{|l|}{ Dam } & \multicolumn{2}{|l|}{ MGD } \\
\hline & MIN & MAX & MIN & MAX \\
\hline PD16 & $N S^{a}$ & NS & $0.0060^{*}$ & NS \\
\hline Milk & NS & $0.0001^{*}$ & $0.0003^{*}$ & 0.0329 \\
\hline Fat & $0.0001^{*}$ & $0.0001^{*}$ & $0.0001^{*}$ & $0.0002^{*}$ \\
\hline Protein & $0.0001^{*}$ & $0.0001^{*}$ & 0.0414 & 0.0285 \\
\hline Fat $\%$ & $0.0001^{*}$ & $0.0001^{*}$ & $0.0001^{*}$ & $0.0001^{*}$ \\
\hline Protein \% & $0.0001^{*}$ & NS & $0.0001^{*}$ & NS \\
\hline SCS & $0.0001^{*}$ & $0.0003^{*}$ & 0.0498 & NS \\
\hline Female fertility & 0.0129 & $0.0001^{*}$ & NS & $0.0411^{*}$ \\
\hline Persistency & $0.0001^{*}$ & $0.0001^{*}$ & $0.0001^{*}$ & $0.0002^{*}$ \\
\hline Herd-life & NS & 0.0235 & $0.0001^{*}$ & NS \\
\hline Dystocia & $0.0001^{*}$ & $0.0001^{*}$ & $0.0001^{*}$ & $0.0002^{*}$ \\
\hline Stillbirth & $0.0001^{*}$ & $0.0001^{*}$ & NS & NS \\
\hline
\end{tabular}

Analysis models are given in Eq. (3)

${ }^{*}$ Significant after Bonferroni's adjustment $(P<0.005)$; the Bonferroni correction was computed based on the 13 traits analyzed

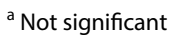

according to the combinations of birth season of the $F_{1}$ and $F_{2}$ cows $\left(F_{0} \times F_{1}\right.$ pregnancy seasons $)$ show that the progenies' PTA for milk, fat and protein yield; and for PD16 were affected in an additive manner. The trends in milk and protein yield are highly correlated $\left(r^{2}=0.98\right)$ and slightly different from those for fat yield versus milk and protein yield $\left(r^{2}=0.74\right.$ and $r^{2}=0.77$, respectively). Positive effects on milk and protein yields were observed for combinations of birth seasons 1 and 2 of $F_{1}$ and $F_{2}$, where birth season of $F_{2}$ seems dominant over that of $F_{1}$ (i.e., exposure to heat stress during $\mathrm{F}_{1}$ pregnancy has a greater effect than that during $\mathrm{F}_{0}$ pregnancy). The most positive effect on fat yield was observed for birth season 2 of $F_{1} \times F_{2}$, which indicates mostly summer-free pregnancies for the $F_{0}$ and $F_{1}$ cows. However, for all these traits, we found the most negative effect on PTA of $F_{3}$ cows for birth season 3 of $F_{1} \times F_{2}$, which indicates tandem $F_{0}$ and $\mathrm{F}_{1}$ second pregnancy semesters during the summer. Nevertheless, for \%fat a significant interaction between the $\mathrm{F}_{0} \times \mathrm{F}_{1}$ pregnancy seasons $(\mathrm{P}<0.01)$ was observed, with a \%fat about two-fold less negative for $F_{3}$ whose $F_{1}$ and $\mathrm{F}_{2}$ ancestors were born in season $2\left(\mathrm{~F}_{0} \times \mathrm{F}_{1}\right.$ summer-free pregnancies).

\section{Discussion}

It is still an open question to what extent epigenetic mechanisms can pass on to future generations environmental effects that have been experienced by their ancestors. The Israeli dairy cattle breeding program is based on intensive data recording, including extensive pedigree, phenotypic and environmental information, which provides an opportunity to study the consequences of possible epigenetics inheritance of the cow ancestors' environment. This allows the assessment of female transmission of transgenerational effects on the $\mathrm{F}_{3}$ cows originating from the exposure of the $F_{0}$ cows to environmental 


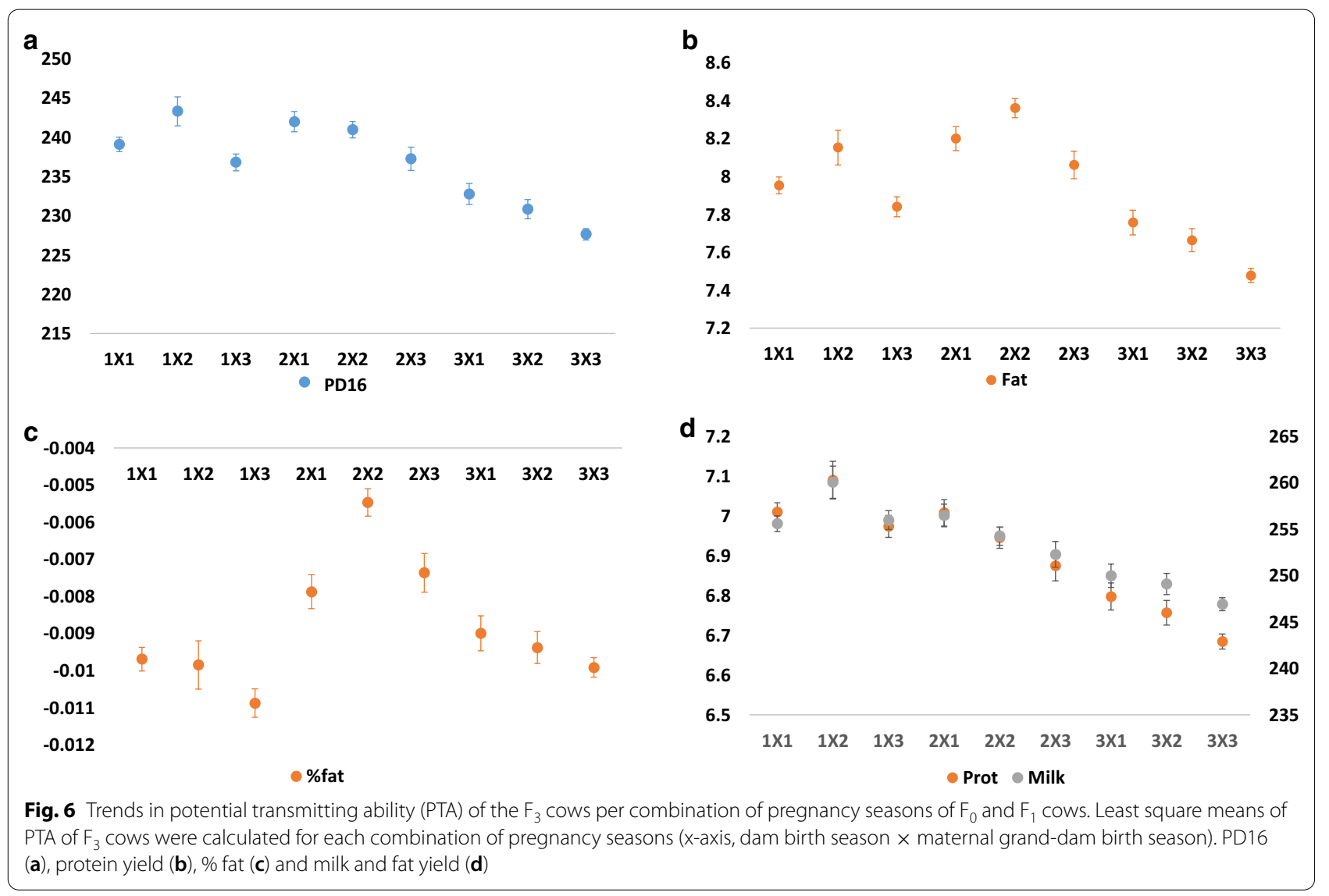

stress [26]. As reflected in this analysis, the incidence of heat stress conditions in Israel has increased in the last decades (Fig. 5), likely due to global warming. Since heat stress can directly affect animal performance and lead to significant economic losses [27], this observation demonstrates the importance of studying the longterm impact of heat stress in livestock, which remains elusive. We found a significant effect of the dam's and grand-dam's birth month on their daughters and granddaughter's PTA (Table 5). The average pregnancy length in cattle is $\sim 280$ days [28], and heat stress occurs in Israel only from June to October [25]. Thus, the cow's birth month is an indicator of the extent of the exposure of her dam to heat stress during pregnancy. Since the statistical model is corrected for the cow's immediate environment, the cow's birth month, and for genetic trends, the likely explanation for the observed impact of the birth month of the $F_{1}$ and $F_{2}$ cows is the environment during the pregnancy of the $F_{0}$ and $F_{1}$ cows, specifically during the summer.

This assumption is supported by the per-month trend analysis. This analysis found that the most positive effect on production and calving traits was when the dam's and grand-dam's birth month was June (Figs. 3 and 4), which did not overlap with summer months during the $\mathrm{F}_{0}$ and $\mathrm{F}_{1}$ pregnancies. With respect to the most negative effect, there were slight differences between production and calving traits. The most negative effect of the dam's and grand-dam's birth month on production traits was during September-December (Fig. 3), which suggests a negative transgenerational impact, caused by the second half of the pregnancy of $F_{0}$ and $F_{1}$ cows occurring during the summer. The most negative effect of the dam's and grand-dam's birth month on calving traits was observed for the $\mathrm{F}_{3}$ cows, whose dam and grand-dams were born from December to March (Fig. 4), which suggests that exposure to heat stress during the second trimester of the pregnancy of the $F_{0}$ and $F_{1}$ cows negatively affects $F_{3}$ progenies.

A recent controlled experiment of a relatively small cohort described a similar effect [10]. In this study, milk production of $\mathrm{F}_{1}$ and $\mathrm{F}_{2}$ cows born to $\mathrm{F}_{0}$ cows that were not cooled during late gestation was lower, providing limited evidence for an intergenerational effect of heat stress.

Although the most likely explanation for the association between the birth month of $F_{1}$ and $F_{2}$ cows with $F_{3}$ performance is the effect of summer during the pregnancy 
of the $F_{0}$ cows, we cannot rule out other possibilities. Thus, to provide direct evidence for the transgenerational effect of heat stress, we analyzed $F_{2}$ and $F_{3}$ performances according to the incidence of heat stress conditions during the pregnancy of $\mathrm{F}_{0}$ cows, and we found a significant association between the heat stress score during the pregnancy of the $F_{0}$ cows and the performances of $F_{2}$ and $F_{3}$ progenies (Table 6 ). This analysis included only $F_{2}$ and $F_{3}$ cows, which are the descendants of $F_{0}$ cows that underwent the second half of their pregnancy during the summer. This suggests that annual differences in heat stress incidence during the second semester pregnancy of $\mathrm{F}_{0}$ cows affected phenotypic expression in the $\mathrm{F}_{2}$ and $\mathrm{F}_{3}$ progenies and provided direct evidence for the broad impact of transgenerational effects of heat stress in cattle. Since the incidence of heat stress is gradually increasing, as indicated in Fig. 5, it is likely that the long-term impact of heat stress will become more prominent, and should be considered when calculating the genetic values of animals.

In the results discussed above, we analyzed only the main effects of the exposure to heat stress conditions of the $F_{0}$ and $F_{1}$ ancestors on their $F_{3}$ progenies. In order for $\mathrm{F}_{3}$ cows to inherit the environmental effect experienced by their $F_{0}$ ancestors, an epigenetic modification that occurred during the formation of the $F_{1}$ gametes must be preserved, at least partially, during the formation of the $\mathrm{F}_{2}$ gametes [29]. Transmission of epigenetics marks could be achieved by either inefficient erasure of the gained epigenetic marks or partial restoration of a stable epigenetic domain lost because of exposure to environmental stress [29]. These possibilities raise the question of the impact of the combinations of different environmental stimuli of the $F_{0}$ and $F_{1}$ cows on the phenotype of the $F_{3}$ cows. To address this question, we analyzed the performance of $\mathrm{F}_{3}$ cows according to different combinations of pregnancy seasons of the $F_{0}$ and $F_{1}$ cows. The performances of $F_{3}$ cows for total milk, protein and fat yield per combination of pregnancy seasons of the $F_{0}$ and $F_{1}$ cows are additive, and that of the $\mathrm{F}_{1}$ seems dominant over that of the $F_{0}$ cows (Fig. 6). This finding supports an inefficient restoration or erasure of the epigenetic marks. The tandem stimuli over two generations of heat stress are likely to maintain the epigenetics modification and thus to produce the most negative effect. The combination of different pregnancy seasons could cause partial loss or restoration of the epigenetic modification and moderate the impact.

Contrary to the additive effect observed for milk, protein, and fat yield, we found that the PTA for \%fat of the $F_{3}$ cows displayed a significant interaction with the $F_{0} \times F_{1}$ pregnancy season combination. There was a two-fold less negative effect on $\%$ fat for the $F_{3}$ cows whose $F_{0} \times F_{1}$ have summer-free pregnancies. We suggest that this finding is not attributable to an epigenetic modification, but rather to the nature of this trait. Percentage fat is the ratio between fat and milk yields. If the correlation between the seasonal combination effects for fat and milk yield was close to unity (as observed for milk and protein yield), no transgenerational effect for \%fat is expected. However, the trends for fat and milk yield are only partially correlated, and the most positive impact for fat yield is due to the season $2 \times$ season 2 combination, which has only an intermediate effect on milk yield. Thus, increased fat yield and decreased milk yield will result in higher \%fat in a pregnancy season combination-dependent manner.

\section{Conclusions}

To the best of our knowledge, these results are the first evidence for transgenerational effects of heat stress through the maternal line on a panel of dairy cattle traits. Our results suggest that the second half of the pregnancy of $\mathrm{F}_{0}$ cows during the hot season causes adverse effects on production and calving traits of their $F_{2}$ and $F_{3}$ progeny. In addition, we found that differences in the incidence of annual heat stress conditions during pregnancies of $\mathrm{F}_{0}$ cows have a strong impact on the performances of $F_{3}$ cows. We expect that this phenomenon may affect the calculation of the cows' genetic value. The combination of different gestation periods between generations $F_{0}$ and $F_{1}$ is expected to moderate the impact of exposure to heat stress and can be taken into account in the reproduction strategy of the herd.

\section{Acknowledgements \\ The authors would like to thank Dan Mishmar for critical reading and for Yali Gershoni for illustrating Fig. 2.}

\section{Authors' contributions}

MG and JIW designed the experiments, performed the analysis, and wrote the manuscript. EE performed data analysis and data collection. All authors read and approved the final manuscript.

\section{Funding}

This research was partially funded by Grants from the Israeli Science Foundation (ISF 946/19) and by a Grant from the Israel Dairy Board for MG. The role of the funding body was in design of the study and collection, analysis, and interpretation of data and in writing the manuscript.

\section{Availability of data and materials}

The data that support the findings of this study are available from Israeli Cattle Breeders Association, but restrictions apply to the availability of these data, which were used under license for the current study, and so are not publicly available. Data are available from the authors upon reasonable request, and with permission of Israeli Cattle Breeders Association.

\section{Declarations}

Ethics approval and consent to participant

Not applicable. 


\section{Consent for publication}

Not applicable.

\section{Competing interests}

The authors declare that they have no competing interests.

\section{Author details}

${ }^{1}$ Israeli Cattle Breeders Association, 3088900 Caesarea, Israel. ${ }^{2}$ The Volcani Center, Department of Ruminant Science, Institute of Animal Sciences, Agricultural Research Organization, 7505101 Rishon LeZion, Israel.

Received: 1 April 2021 Accepted: 27 August 2021

Published online: 06 September 2021

\section{References}

1. Pasqui M, Di Giuseppe E. Climate change, future warming, and adaptation in Europe. Anim Front. 2019;9:6-11.

2. Collier RJ, Dahl GE, Vanbaale MJ. Major advances associated with environmental effects on dairy cattle. J Dairy Sci. 2006;89:1244-53.

3. Wolfenson D, Roth Z. Impact of heat stress on cow reproduction and fertility. Anim Front. 2019;9:32-8.

4. Collier RJ, Baumgard LH, Zimbelman RB, Xiao Y. Heat stress: physiology of acclimation and adaptation. Anim Front. 2018;29:12-9.

5. Monteiro APA, Tao S, Thompson IMT, Dahl GE. In utero heat stress decreases calf survival and performance through the first lactation. J Dairy Sci. 2016;99:8443-50.

6. Skibiel AL, Dado-Senn B, Fabris TF, Dahl GE, Laporta J. In utero exposure to thermal stress has longterm effects on mammary gland microstructure and function in dairy cattle. PLoS One. 2018;13:e0206046.

7. Heard E, Martienssen RA. Transgenerational epigenetic inheritance: myths and mechanisms. Cell. 2014:157:95-109.

8. Larson JE, Lamb GC, Funnell BJ, Bird S, Martins A, Rodgers JC. Embryo production in superovulated Angus cows inseminated four times with sexed-sorted or conventional, frozen-thawed semen. Theriogenology. 2010;73:698-703.

9. Perez MF, Lehner B. Intergenerational and transgenerational epigenetic inheritance in animals. Nat Cell Biol. 2019;21:143-51.

10. Laporta J, Ferreira FC, Ouellet V, Dado-Senn B, Almeida AK, De Vries A, et al. Late-gestation heat stress impairs daughter and granddaughter lifetime performance. J Dairy Sci. 2020;103:7555-68.

11. Torrens C, Poston L, Hanson MA. Transmission of raised blood pressure and endothelial dysfunction to the F2generation induced by materna protein restriction in the $\mathrm{F} 0$, in the absence of dietary challenge in the $\mathrm{F} 1$ generation. Br J Nutr. 2008;100:760-6.

12. Jimenez-Chillaron JC, Isganaitis E, Charalambous M, Gesta S, PentinatPelegrin T, Faucette RR, et al. Intergenerational transmission of glucose intolerance and obesity by in utero undernutrition in mice. Diabetes. 2009:58:460-8.
13. Painter RC, Roseboom TJ, Bleker OP. Prenatal exposure to the Dutch famine and disease in later life: an overview. Reprod Toxicol. 2005;20:345-52.

14. Lumey LH. Decreased birthweights in infants after maternal in utero exposure to the Dutch famine of 1944-1945. Paediatr Perinat Epidemiol. 1992;6:240-53.

15. Lumey LH, Stein AD, Ravelli ACJ. Timing of prenatal starvation in women and birth weight in their first and second born offspring: the Dutch famine birth cohort study. Eur J Obstet Gynecol Reprod Biol. 1995;61:23-30.

16. Pembrey ME. Male-line transgenerational responses in humans. Hum Fertil (Camb). 2010;13:268-71

17. Weller JI, Ezra E. Genetic analysis of the Israeli Holstein dairy cattle population for production and nonproduction traits with a multitrait animal model. J Dairy Sci. 2004;87:1519-27.

18. Weller Jl, Ezra E, Leitner G. Genetic analysis of persistency in the Israeli Holstein population by the multitrait animal model. J Dairy Sci. 2006:89:2738-46.

19. Weller J, Ezra E. Environmental and genetic factors affecting cow survival of Israeli Holsteins. J Dairy Sci. 2015;98:676-84.

20. Weller J, Ezra E. Genetic analysis of calving traits by the multi-trait individual animal model. J Dairy Sci. 2016;99:427-42.

21. Honig H, Miron J, Lehrer H, Jackoby S, Zachut M, Zinou A, et al. Performance and welfare of high-yielding dairy cows subjected to 5 or 8 cooling sessions daily under hot and humid climate. J Dairy Sci. 2012;95:3736-42.

22. Moran J. Tropical dairy farming: feeding management for small holder dairy farmers in the humid tropics. Totnes: Landlinks Press; 2005. p. 275.

23. SAS Institute Inc. SAS/ACCESS ${ }^{\circledR} 9.4$ Interface to ADABAS. Cary: SAS Institute Inc.; 2013.

24. Weller JI, Ron M. Genetic analysis of fertility traits in Israeli Holsteins by linear and threshold models. J Dairy Sci. 1992;75:2541-8.

25. Flamenbaum I, Galon N. Management of heat stress to improve fertility in dairy cows in Israel. J Reprod Dev. 2010;56:S36-41.

26. Skinner MK. What is an epigenetic transgenerational phenotype?. F3 or F2. Reprod Toxicol. 2008;25:2-6.

27. St-Pierre NR, Cobanov B, Schnitkey G. Economic losses from heat stress by US livestock industries. J Dairy Sci. 2003;86:E52-77.

28. Nogalski Z, Piwczyński D. Association of length of pregnancy with other reproductive traits in dairy cattle. Asian-Australas J Anim Sci. 2012;25:22-7

29. Klosin A, Lehner B. Mechanisms, timescales and principles of transgenerational epigenetic inheritance in animals. Curr Opin Genet Dev. 2016;36:41-9.

\section{Publisher's Note}

Springer Nature remains neutral with regard to jurisdictional claims in published maps and institutional affiliations.

Ready to submit your research? Choose BMC and benefit from

- fast, convenient online submission

- thorough peer review by experienced researchers in your field

- rapid publication on acceptance

- support for research data, including large and complex data types

- gold Open Access which fosters wider collaboration and increased citations

- maximum visibility for your research: over 100M website views per year

At BMC, research is always in progress.

Learn more biomedcentral.com/submissions 